\title{
Lassen Sie sich als FVDZ-Mitglied bei einer Weihnachtsaktion einen exklusiven Preisvorteil bieten!
}

Zum Ende des Jahres 2015 möchte die ORIDIMA Dentalinstrumente GmbH \& Co. KG in Zusammenarbeit mit Dynadent - Service für Zahnärzte GmbH - allen Mitgliedern des FVDZ bei einer Weihnachtsaktion einen besonderen Vorteil anbieten (gültig bis zum 22.12.2015): Beim Kauf von vier hochwertigen NSK-Winkelstücken (Rot, Grün oder Blau) gibt es unter dem Motto 4+2 zwei weitere NSK-Winkelstücke geschenkt.

\section{NSK-Winkelstück Rot X95L}

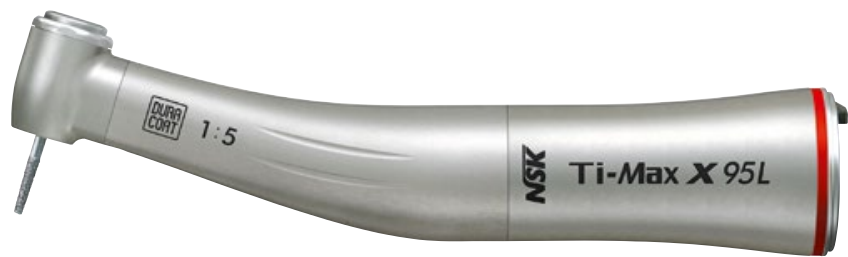

Das X95L ist für Instrumente mit FG-Schaft, hat eine Übersetzung von 1:5, ein 4-fach-Wasserstrahlsystem sowie ein Keramik-Kugellager. Preis: 799 Euro

Beispiel: vier Stück X95L mit Berechnung und zwei Stück X95L ohne Berechnung

\section{NSK-Winkelstück Grün X15L}

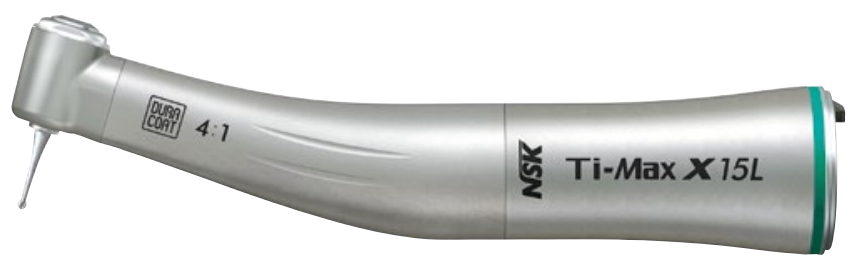

Das X15L hat eine Untersetzung von 4:1 und ein 1-fach-Wasserstrahlsystem.

Preis: 698 Euro

Beispiel: vier Stück X15L mit Berechnung und zwei Stück X15L ohne Berechnung

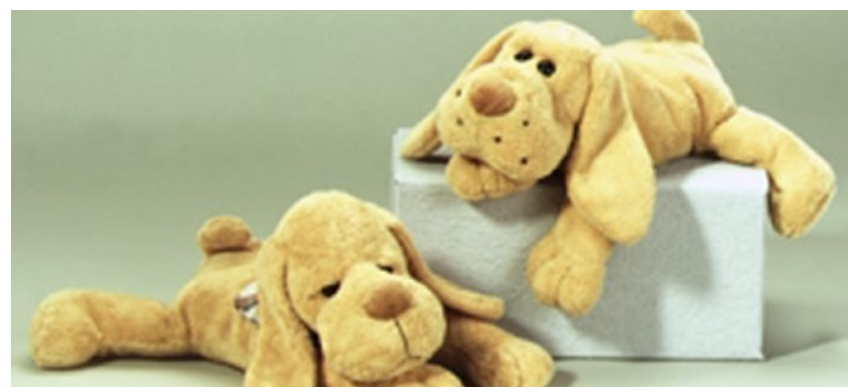

Uns zwei ORI-Lillys gibt es auch noch dazu (je ca. $28 \mathrm{~cm}$ )
NSK-Winkelstück Blau X25L

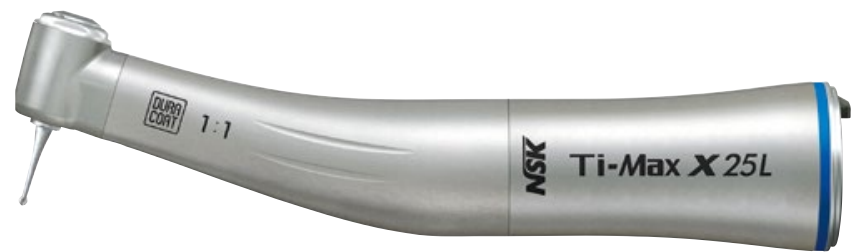

Das X25L hat eine Übersetzung von 1:1 und ein 1-fach-Wasserstrahlsystem.

Preis: 599 Euro

Beispiel: vier Stück X25L mit Berechnung und zwei Stück X25L ohne Berechnung

Alle Winkelstücke haben einen ISO-Anschluss, einen massiven Titankörper (besonders leicht), eine kratzfeste Oberfläche (DURACOAT-Beschichtung), eine Zellglasoptik, ein Clean-Head-System sowie ein Ultra-Push-Selbstspannfutter zum schnellen Instrumentenwechsel. Die NSK-Herstellergarantie beträgt zwei Jahre.

Werden beispielsweise vier rote Winkelstücke X95L bestellt (vier Stück à 799 Euro), dann sind zusätzlich zwei Winkelstücke gratis (zum Beispiel zwei Stück X95L, zwei Stück X15L, zwei Stück X25L oder zwei Stück gemischt). Dabei sind im Fall von verschiedenen Winkelstücken immer die preisgünstigeren ohne Berechnung. Im Service-Coupon können Sie die Winkelstücke nach Ihrem individuellen Bedarf zusammenstellen. Dabei können Sie pro vier Winkelstücke mit Berechnung zwei zusätzliche Winkelstücke ohne Berechnung auswählen.

Nutzen Sie den Service-Coupon auf Seite 79 für Ihre Bestellung. Die Versandkosten übernimmt ORIDIMA.

Alle Preise zzgl. MwSt.. 